\title{
Nurse-patient consultations in primary care: do patients disclose their concerns?
}

- Objective: To quantify the extent to which patients disclose their concerns to community nurses during wound care consultations.

- Method: Using an 'observation checklist' based on themes and subthemes that were identified in a previous study of the same patients, 20 wound care consultations were observed.The non-participant observer completed the checklist and made field notes regarding the context and nature of interactions.

- Results: Patient participants had 160 opportunities to raise concerns regarding previously-identified pain, exudate and odour, yet they did not do so on 64 (40\%) occasions. They had 28,32 and 84 opportunities to raise emotional, wound care and daily living issues, respectively, and they did not on 16 (56\%), $3(9 \%)$ and 32 (38\%) occasions. Overall, patients did not raise $38 \%$ of their concerns. Of the concerns that were raised, $8 \%$ were either not acknowledged or were disregarded by their community nurse.

- Conclusion: If these data are representative, this has profound implications for person-centred care and shared decision-making models of care, which are predicated on patients articulating their needs. They also have implications for the development of practitioners' communication and consulting skills. - Declaration of interest: This study was funded by NHSWest Midlands Strategic Health Authority. The authors have no conflicts of interest to declare.

venous leg ulcers; community nursing; consultations; patient-centred care; observation; interviews

J. Green,' MSc, Lecturer and PhD Research Fellow; R. Jester, $2,3 \mathrm{PhD}$,

Adjunct Professor and Head of Adult Nursing and Midwifery;

R. McKinley,' PhD,

Professor of Education

in General Practice,

Keele Medical School;

A. Pooler,' PhD, Lecturer and Post-Doctoral

Research Fellow;

I Keele University School of Nursing and Midwifery, Clinical Education Centre, University Hospital of North Staffordshire NHS Trust, Stoke-on-Trent, UK.

2 School of Nursing and Midwifery, Griffith University, Queensland, Australia.

3 Faculty of Health and Social Care, London South Bank University; Email:j.green@

keele.ac.uk

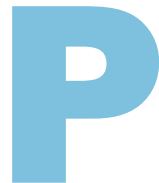

atient-centred care (PCC) expands the focus of clinical encounters to include the patient's psychological and social context. ${ }^{1}$ It embraces shared decisionmaking (SDM), wherein health-care decisions are jointly made by the patient and practitioner. ${ }^{2}$ Stewart suggested that consultations result in improved health outcomes, largely through their impact on patient behaviour. ${ }^{3}$ With greater agreement between patient and practitioner and, consequently, increased concordance with a management plan, PCC and SDM should result in enhanced behaviour and improved health outcomes, with a greater likelihood of improvements in functional status, self-care and patient satisfaction. ${ }^{4}$ PCC is recognised as an indicator of the quality of health care..$^{5-7}$

Despite the relative simplicity of PCC and SDM, medical and nursing practitioners often fail to elicit patients' concerns and negotiate treatment options. ${ }^{8-10}$ In a series of observed general practice consultations, it was found that $54 \%$ of patient problems and $45 \%$ of patient concerns were subsequently unknown to the doctor. ${ }^{11} \mathrm{~A}$ similar series of observed consultations found that the general practitioner only attempted to elicit the patient's view of their diagnosis in $6 \%$ of consultations, ${ }^{12}$ and another study found that physicians and patients failed to agree on the presenting problem in as many as 50\% of consultations. ${ }^{13}$ Nurses also fail to communicate well on occasion, with a tendency to approach patients when dealing with administrative and functional issues. ${ }^{14,15}$ Patients often feel intimidated and reluctant to express their needs, ${ }^{16}$ which is compounded by poor clinical communication. ${ }^{10,15}$

\section{Venous leg ulcers}

Chronic venous leg ulceration (VLU) is common, intractable and often recurrent. ${ }^{17,18}$ The care of such patients is often focused on healing the ulcer ${ }^{19,20}$ and frequently neglects to address issues of pain, odour, depression, anxiety and social isolation. ${ }^{21}$ The impact of VLU on the patient and his or her quality of life (QoL) is consistently underestimated, ${ }^{17,22}$ so offers a rich context in which to investigate PCC and its impact on patient outcomes. This article describes the second phase of a two-phase study to investigate PCC in people with VLU.

\section{Method}

In phase I, we systematically identified factors that were important to people with chronic VLU, which 


\section{Table I. Consultation checklist items}

\section{Symptoms}

Presence of pain:

- Cause of pain

- Type of pain

- Timing and duration

- Use and effectiveness of analgesia

Advice on pain management:

- Comfort of dressing

- Discomfort during dressing change

Exudate:

- Odour

Depression:

- Fears and concerns

- Self-image

- Fear of people's reactions

- Fear of recurrence

Wound management

Update on the wound:

- Wound measurement

- Nurse advice

- Patient understanding of dressings

Effects on daily life

\section{Sleep}

Personal hygiene

Leg washing

Mobility

Clothes and shoes

Opportunities for work and leisure:

- Isolation

- Relationships

- Financial issues

are briefly described in Fig $1 .^{23}$ In phase II (reported here), we observed five of the same people's wound care consultations. Using a checklist based on the findings of phase I, we were able to identify which factors were raised by patients during these consultations and the extent to which they were addressed by experienced nurses. This was preparatory work for a pilot study of an intervention to increase PCC in VLU care.

\section{Study population}

Nurse participants were recruited by advertising to community nurse teams in two primary care trusts. Inclusion criteria were that the nurse had been working in primary care for at least 6 months, had patients with chronic VLU on his or her caseload,

\section{Fig I.Themes and subthemes identified from interviews ${ }^{23}$}
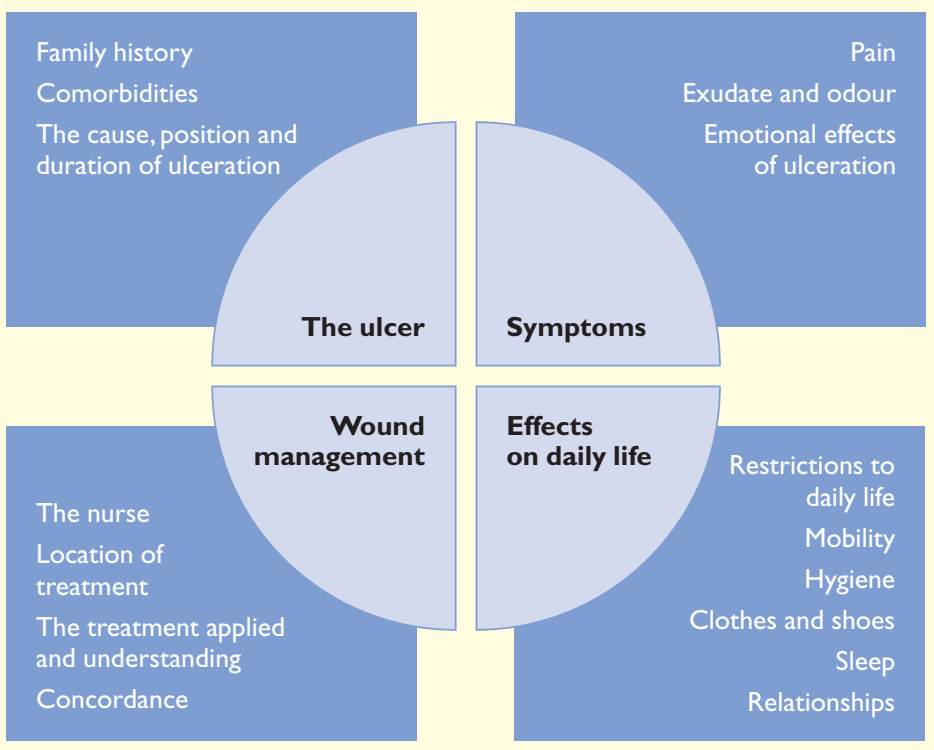

and consented to the recruitment of these patients into the study with subsequent peer observation of consultations.

The patient participants were recruited from nurse participants' caseloads. These nurses gave potentially eligible patients a letter of invitation, a participant information leaflet, a consent form and an addressed, freepost envelope. Potential participants contacted JG, who formally consented those who were eligible. Patient participant inclusion criteria were VLU for more than 6 weeks and competence to provide informed consent.

Thirteen community nurses were recruited into the study. All were women and they had worked in primary care for a median of 5 years (range: 6 months to 20 years). Nine patients (four male; 44\%) were recruited for the phase I interviews (median age: 76 years; range: 39-99 years). Five patients (three male; 60\%) were recruited to phase II (median age: 76 years; range: 39-86 years), of which two had healed ulcers, one was in hospital following a fall, and one had been discharged.

Ethical approval for the study was granted by the Mid Staffordshire NHS Foundation Trust Local Research Ethics Committee.

\section{Data collection}

Having identified themes and subthemes from the phase I interviews (Fig 1), ${ }^{23,24} \mathrm{JG}$ and AP independently developed checklist items from these themes and subthemes. They agreed on a checklist of 28 items. This was verified in discussion with RJ. The checklist formed a predetermined observation schedule (Table 1). ${ }^{25}$

For ease of completion, tick, comment and 'scoring' 
Table 2. Scores for checklist themes

\begin{tabular}{ll} 
Score & Criterion \\
\hline 0 & Theme not raised by nurse or patient \\
\hline 1 & Nurse did not identify cue from patient \\
\hline 2 & Nurse picked up cue only \\
\hline 3 & $\begin{array}{l}\text { Nurse identified patient cue and asked about } \\
\text { the issue }\end{array}$ \\
\hline 4 & Nurse picked up cue and partially dealt with it \\
\hline 5 & Nurse picked up cue and dealt with it fully
\end{tabular}

boxes were included in the checklist, thus minimising distraction for the researcher when recording whether an issue was raised by the patient or the nurse participant and the depth to which it was explored. A 'scoring' scale, based on those used in similar studies, ${ }^{26}$ facilitated rapid assessment and the recording of depth of exploration of each theme (Table 2).

\section{Procedure}

JG observed four successive consultations between the patient and nurse participants, either in the patient's home or at the clinic, to determine the extent to which themes and subthemes patients had disclosed during phase I were being explored in subsequent consultations with members of the community nursing team. JG had the role of non-participant observer, completing the checklist during consultations and making field notes regarding the context and nature of interactions immediately after consultations. Each observation lasted for between 20 and 30 minutes.

Data collection for both phases was conducted between January 2010 and December 2011, and data analysis was concurrent and cumulative. Analysis included the proportion of consultations at which patient participants raised themes that they had already disclosed during phase I, and the extent to which participating nurses addressed these themes.

\section{Results}

Five patient participants consulted with 13 nurse participants in 20 observed consultations. Results for the themes and subthemes are displayed in Table 3. Overall, $38 \%$ of concerns were not disclosed by patients. Of the $62 \%$ that were disclosed, $8 \%$ were missed or ignored by the nurse, $30 \%$ were discussed but not managed and $24 \%$ were managed, at least partially. These results are statistically significant $\left(\chi^{2}=55.0 ; \mathrm{df}=20\right.$; $\mathrm{p}<0.0001)$.

It was found that $56 \%$ of patient participants' emotional issues were not raised, whereas $91 \%$ of their wound care issues were. Based on these findings, it may be that concerns relating to the emotional effects of VLU are less likely to be disclosed and managed than concerns relating to wound management.

\section{Discussion}

This small group of people, in whom concerns had been identified, did not raise $38 \%$ of their concerns during four consecutive consultations with their community nurses. Of the $62 \%$ of concerns that were raised, the nurse overlooked or 'blocked' $8 \%$ and discussed but did not act on $30 \%$. Thus only a quarter (24\%) of patients' concerns were addressed to some degree during the consultation.

Fig 2 combines Stewart's ${ }^{3}$ mechanism to explain the link between consultations and improved patient outcomes with the results of this study. We found that $38 \%$ of patients' concerns were never disclosed and thus 'lost' to the consultation, a fur-

Table 3. Observation results

\begin{tabular}{|c|c|c|c|c|c|c|}
\hline $\begin{array}{l}\text { Issue (total number of } \\
\text { potential occurrences } \\
\text { of each issue) }\end{array}$ & $\begin{array}{l}\text { Not raised } \\
(\text { score }=0)\end{array}$ & $\begin{array}{l}\text { Cue not } \\
\text { identified } \\
(\text { score }=I)\end{array}$ & $\begin{array}{l}\text { Cue blocked } \\
\text { (score=2) }\end{array}$ & $\begin{array}{l}\text { Discussed } \\
(\text { score }=3)\end{array}$ & $\begin{array}{l}\text { Partially } \\
\text { dealt with } \\
(\text { score }=4)\end{array}$ & $\begin{array}{l}\text { Fully dealt } \\
\text { with } \\
\text { (score=5) }\end{array}$ \\
\hline Pain $(n=132)$ & $55(42 \%)$ & $9(7 \%)$ & I (I\%) & $36(27 \%)$ & $9(7 \%)$ & $22(16 \%)$ \\
\hline Exudate and odour $(n=28)$ & $9(32 \%)$ & I (4\%) & I (4\%) & $5(18 \%)$ & I (4\%) & II (38\%) \\
\hline Emotional effects $(n=28)$ & $16(56 \%)$ & $2(7 \%)$ & I (4\%) & $8(29 \%)$ & $0(0 \%)$ & I (4\%) \\
\hline Wound management $(n=32)$ & $3(9 \%)$ & $0(0 \%)$ & I (3\%) & $9(28 \%)$ & $4(13 \%)$ & 15 (47\%) \\
\hline Effects on daily life $(n=84)$ & $32(38 \%)$ & $8(10 \%)$ & I (I\%) & 33 (39\%) & $3(4 \%)$ & $7(8 \%)$ \\
\hline Total $(n=304)$ & II 5 (38\%) & $20(7 \%)$ & $5(1 \%)$ & 91 (30\%) & $17(6 \%)$ & $56(18 \%)$ \\
\hline
\end{tabular}


Fig 2. Results flow chart

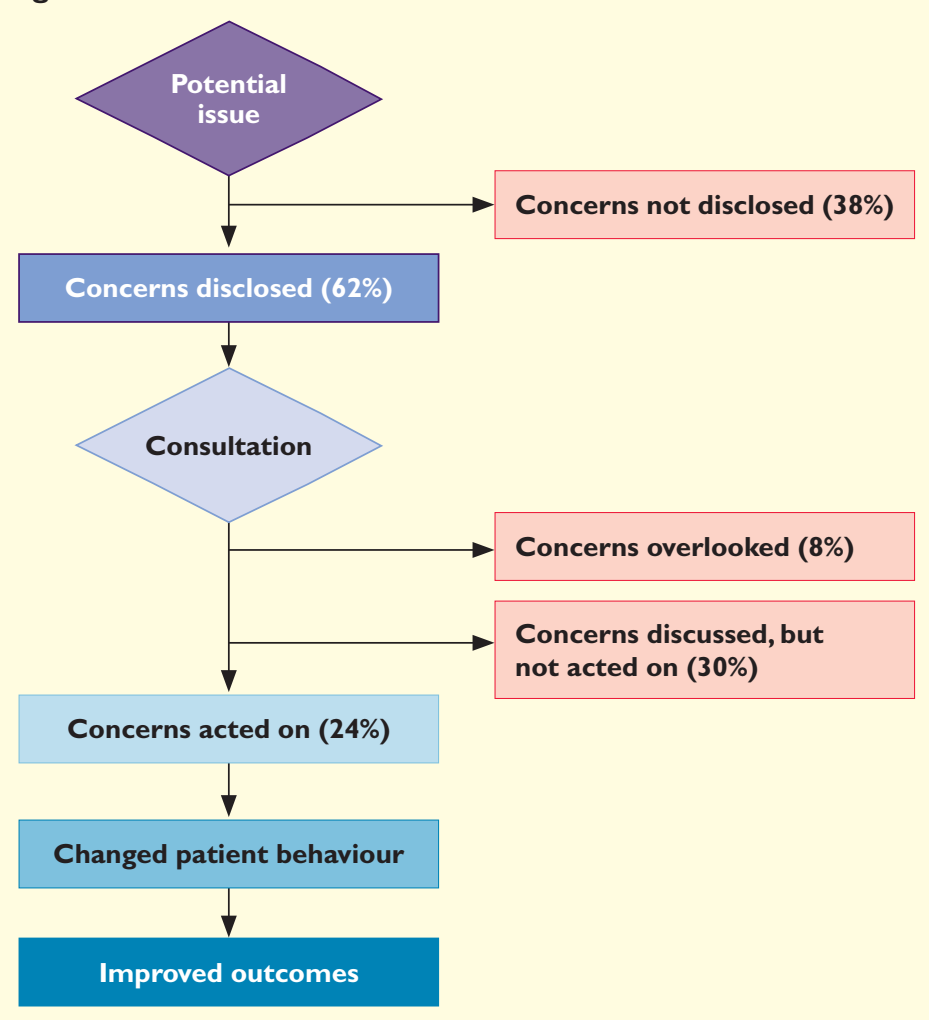

ther 38\% were either ignored by the nurse or were discussed, but without any proposed or agreed changes in care, and only a quarter (24\%) of patients' concerns were acted upon.

These results echo those of Stewart et al., ${ }^{11}$ who demonstrated that some $50 \%$ of patients' problems and concerns were unknown to the doctor (although the proportion of concerns that the patient failed to disclose was not identified). The present study unpicks these data to reveal that many concerns may not have been raised by patients during consultations. The effectiveness of consultation relies on both members of the patient-practitioner dyad engaging in SDM behaviours. ${ }^{27}$ The particular importance of this study is to show that effective interventions will likely include enhancement of patient disclosure as well as clinician training.

Strengths of this study include having a single observer, the rigorous identification of patients' concerns (through paired, thematic analysis), development of the consultation checklist, the multiple observations (which increased the likelihood of observing an issue being raised and reduced the Hawthorne effect ${ }^{28}$ ) and the careful field notes taken by JG. It adds to previous work by demonstrating that of the large proportion of patient problems and concerns of which practitioners may not be aware, ${ }^{11}$ half were not disclosed by patients and half were either not acknowledged or ignored by practitioners.

Weaknesses of this study include the potential for observation to affect the patient-practitioner interaction and the possibility that issues and concerns identified at the initial interview may have resolved before the observed consultations. We assumed that all concerns were still current and that patients' ulceration was ongoing. ${ }^{18}$ JG's field notes indicate that this was the case.

Recommendations to enhance PCC generally focus on interventions that change practitioner behaviour, such as enhancing consultation style, ${ }^{29}$ or patientmediated interventions, such as decision aids. ${ }^{30,31}$ This study offers a rich and unique, albeit situated, insight into the gap between the concerns that people may have with respect to their condition and those that they share with their health professionals. A large proportion of patient need is not being disclosed and interventions to enable patient disclosure may result in substantial gains. ${ }^{32,33}$ This has important consequences for PCC.

Patient-practitioner communication has long been a subject of research ${ }^{34}$ and barriers to effective communication have been attributed to: 'asymmetry of the physician-patient relationship' (p. 32); $;^{35}$ poor communication; ${ }^{36}$ organisational constraints; ${ }^{37}$ delays in answering patients' questions; ${ }^{38}$ and a focus on functional activities. ${ }^{15}$ Research has largely focused on practitioners, with little attention being paid to patients' non-disclosure of their problems and concerns. This paper quantifies the relative importance of these facets of poor communication: for every issue that was raised by a patient and not dealt with by a nurse, another issue was not disclosed. The focus of research into patientpractitioner communication must be widened to include the patient.

\section{Conclusion}

The findings of this study-albeit one that is embedded in a local clinical context-offer insight into the nature of information-sharing during consultations, and the nature of PCC and SDM. Our findings have implications for people with VLU and those who provide their wound care, and they offer food for thought for all practitioners who are seeking to provide PCC and SDM. We may thoroughly address the expressed agenda of our patients, and yet still miss over a third of the potential of consultations.

PCC is the product of effective collaboration between patients and health professionals. Unless patients are enabled to articulate their concerns, many issues will not be acknowledged and, therefore, not be managed. Urgent work is therefore needed to determine how we, as health-care practitioners, can enable our patients to share their concerns, so that we can address them together and improve health outcomes. 


\section{References}

I Stewart, M., Meredith, L., Brown,

J.B., Galajda, J.The influence of older patient-physician communication on health and health-related outcomes. Clin Geriatr Med. 2000; 16: 25-36. 2 Légaré, F., Ratté, S., Stacey, D. et al. Interventions for improving the adoption of shared decision making by healthcare

professionals. Cochrane Database Syst Rev. 2010; 5: CD006732.

3 Stewart, M. Continuity, care, and commitment: the course of patient-clinician relationships. Ann Fam Med. 2004; 2: 388-90.

4 Ekman, l., Swedberg, K., Taft, C., et al. Person-centered care —ready for prime time. Eur J Cardiovasc Nurs. 201 I; 10: 248-25I.

5 Lewin, S., Skea, Z., Entwistle,V.A et al. Interventions for providers to promote a patient-centred approach in clinical consultations. Cochrane Database Syst Rev. 2001; 4: CD003267.

6 Department of Health. The NHS Plan: A Plan for Investment, Plan for Reform. The Stationery Office, 2000.

7 Department of Health. The National Service Framework for Older People. The Stationery Office, $200 \mathrm{l}$.

8 Ley, P., Whitworth, M.A., Skilbeck, C.E. et al. Improving doctor-patient communication in general practice.J R Coll Gen Pract. 1976; 26: 720-724.

9 Griffin, S.J., Kinmouth,A., Veltman, M. et al. Effect on health-related outcomes of interventions to alter the interaction between patients and practitioners: a systematic review of trials. Ann Fam Med. 2004; 2 : 595-608.
10 Wong, K., van der Horst, M. Patient and Family-Focused Care. Just Ask Just Tell. RGP, 2010. I I Stewart, M., McWhinney, I.R., Buck, C.W.The doctor/patient relationship and its effect upon outcome. J R Coll Gen Pract. 1979; 29: 77-81.

I 2 Tuckett, D., Boulton, M., Olson, C.,Williams, A. Meetings between Experts:An Approach to Sharing Ideas in Medical Consultations. Routledge, 1985.

I 3 Stewart, M. Effective physicianpatient communication and health outcomes: a review. CMAJ. 1995 ; I52: |423-1433.

I 4 Binnie,A.,Titchen,A. Freedom to Practise. The Development of Patient-Centred Nursing. Butterworth Heinemann, 1999. I 5 McCabe, C. Nurse-patient communication: an exploration of patients' experiences. J Clin Nurs. 2004; | 3: 4|-49.

16 Helman C. Culture, Health and Illness (5th edn). Hodder Arnold, 2007.

17 Heit, J.A., Rooke, T.W. Silverstein, M.D. et al. Trends in the incidence of venous stasis syndrome and venous ulcer: a 25-year population-based study. Vasc Surg. 200I; 33: 1022-1027.

I 8 Posnett, J., Franks, P.The costs of skin breakdown and ulceration in the UK. In: Marks, R. (ed). Skin Breakdown:The Silent Epidemic. Smith and Nephew Foundation, 2007. 19 Rich,A., McLachlan, L. How living with a leg ulcer affects people's daily life: a nurse-led study. JWound Care. 2003; I2: 5I-54. 20 Persoon, A., Heinen, M., van derVleuten, $C$. et al. Leg ulcers: a review of their impact on daily life. J Clin Nurs. 2004; I 3: 34 I-354.
2 I Jones, J.E., Nelson, E.A. Skin grafting for venous leg ulcers. Cochrane Database Syst Rev. 2005; I: CD00I 737.

22 Callam, M.J., Ruckley, C.V., Harper, D.R., Dale, J.J. Chronic ulceration of the leg: extent of the problem and provision of care. BMJ. 1985; 290: |855-1856. 23 Green, J., Jester, R., McKinley, R., Pooler, A. Patient perspectives of their leg ulcer journey. J Wound Care. 2013; 22: 58-66.

24 Braun, V., Clarke,V. Using thematic analysis in psychology. Qual Res Psychol. 2006; 3: 77-101.

25 Fetterman, D. Ethnography: Step-by-Step (3rd ed). SAGE Publications Ltd., 20I0.

26 Henbest, R.J., Stewart, M.A Patient-centredness in the consultation. I:A method for measurement. Fam Pract. 1989; 6 : 249-253.

27 LeBlanc, A., Kenny, D.A. O'Connor, A.M., Légaré, F. Decisional conflict in patients and their physicians: a dyadic approach to shared decision making. Med Decis Making. 2009; 29: 6I-68.

28 Franke, R.H., Kaul, J.D.The Hawthorne experiments: first statistical interpretation. Am Sociol Rev. 1978; 43: 623-643.

29 Cochrane Effective Practice and Organisation of Care Group. Data collection checklist. epoc.cochrane.org [Last accessed: 23/I//3]

30 Kinnersley, P., Edwards, A. Hood, K. et al. Interventions before consultations for helping patients address their information needs. Cochrane Database Syst Rev. 2007; 3 . CD004565.
3I O'Connor, S.J. Building the knowledge base for patientcentred care: improving the use of qualitative study finding through meta-analysis and systematic reviews. Eur J Cancer Care (Engl). 2009; I8: 433-436. 32 McKinley, R.K., Middleton, J.F. What do patients want from doctors? Content analysis of written patient agendas for the consultation. Br J Gen Pract. 1999; 49: 796-800.

33 Middleton, J.F., McKinley, R.K., Gillies, C.L. Effect of patient completed agenda forms and doctors' education about the agenda on the outcome of consultations: randomised controlled trial. BMJ. 2006; 332 1238-1242.

34 McKenzie, P.J. Communication barriers and information-seeking counterstrategies in accounts of practitioner-patient encounters. Libr Inf Sci Res. 2002; 24: 3 I-47. 35 Jordan, B. Authoritative knowledge and its construction. In: Davis-Floyd, R.E., Sargent, C.F. (eds). Childbirth and Authoritative Knowledge: Cross-Cultural Perspectives. University of California Press, 1997.

36 Jarrett, N., Payne, S. A selective review of the literature on nursepatient communication: has the patient's contribution been neglected? J Adv Nurs. 1995; 22 : 72-78.

37 Pritchard, P. Doctors, patients and time. In: Frankenberg, R. (ed) Time, Health and Medicine. SAGE Publications Ltd., 1992.

38 Roberts, F.The interactional construction of asymmetry: The medical agenda as a resource for delaying response to patient questions. Sociol Q. 2000; 41 . $151-170$

\section{Dermatology Handbook}

\section{The professionals" guide to product selection}

- Need to know what new products are available at your fingertips?

- Ever wonder which product is the best for your patient?

The professionals comprehensive guide todermatology product selection

\section{www.dermatologyhandbook_co.uk}

